Send your completed paper to Sandy Rutter at rutter@asabe.org by June 22, 2012 to be included in the ASABE Online Technical Library.

Please have Word's AutoFormat features turned OFF and do not include live hyperlinks. For general information on writing style, please see

http://www.asabe.org/media/19670/asabe guide for authors.pdf

This page is for online indexing purposes.

\begin{tabular}{|l|l|l|l|l|}
\hline First Name & Middle Name & Surname & Role & Email \\
\hline David & & Kohanbash & $\begin{array}{l}\text { ASABE } \\
\text { Member }\end{array}$ & $\begin{array}{l}\text { dkohanba@c } \\
\text { mu.edu }\end{array}$ \\
\hline
\end{tabular}

Affiliation

\begin{tabular}{|l|l|l|}
\hline Organization & Address & Country \\
\hline Carnegie Mellon University & $\begin{array}{l}5000 \text { Forbes Ave Pittsburgh, } \\
\text { PA 15213 }\end{array}$ & USA \\
\hline
\end{tabular}

Author(s)

\begin{tabular}{|l|l|l|l|l|}
\hline First Name & Middle Name & Surname & Role & Email \\
\hline Abhinav & & Valada & & $\begin{array}{l}\text { avalada@cm } \\
\text { u.edu }\end{array}$ \\
\hline
\end{tabular}

Affiliation

\begin{tabular}{|l|l|l|}
\hline Organization & Address & Country \\
\hline Carnegie Mellon University & $\begin{array}{l}5000 \text { Forbes Ave Pittsburgh, } \\
\text { PA 15213 }\end{array}$ & USA \\
\hline
\end{tabular}

Author(s)

\begin{tabular}{|l|l|l|l|l|}
\hline First Name & Middle Name & Surname & Role & Email \\
\hline George & & Kantor & & $\begin{array}{l}\text { kantor@cmu. } \\
\text { edu }\end{array}$ \\
\hline
\end{tabular}

Affiliation

\begin{tabular}{|l|l|l|}
\hline Organization & Address & Country \\
\hline Carnegie Mellon University & $\begin{array}{l}5000 \text { Forbes Ave Pittsburgh, } \\
\text { PA 15213 }\end{array}$ & USA \\
\hline
\end{tabular}

Publication Information

\begin{tabular}{|l|l|}
\hline Pub ID & Pub Date \\
\hline 121337112 & 2012 ASABE Annual Meeting Paper \\
\hline
\end{tabular}

The authors are solely responsible for the content of this technical presentation. The technical presentation does not necessarily reflect the official position of the American Society of Agricultural and Biological Engineers (ASABE), and its printing and distribution does not constitute an endorsement of views which may be expressed. Technical presentations are not subject to the formal peer review process by ASABE editorial committees; therefore, they are not to be presented as refereed publications. Citation of this work should state that it is from an ASABE meeting paper. EXAMPLE: Author's Last Name, Initials. 2012. Title of Presentation. ASABE Paper No. 12----. St. Joseph, Mich.: ASABE. For information about securing permission to reprint or reproduce a technical presentation, please contact ASABE at rutter@asabe.org or 269-932-7004 (2950 Niles Road, St. Joseph, MI 49085-9659 USA). 


\title{
Irrigation Control Methods for Wireless Sensor Network
}

\section{David Kohanbash}

Carnegie Mellon University, 5000 Forbes Ave. Pittsburgh, PA 15213, dkohanba@cmu.edu.

\section{Abhinav Valada}

Carnegie Mellon University, 5000 Forbes Ave. Pittsburgh, PA 15213, avalada@cmu.edu

\section{George Kantor}

Carnegie Mellon University, 5000 Forbes Ave. Pittsburgh, PA 15213, kantor@cmu.edu.

\author{
Written for presentation at the \\ 2012 ASABE Annual International Meeting \\ Sponsored by ASABE \\ Hilton Anatole \\ Dallas, Texas \\ July 29 - August 1, 2012
}

Abstract. Wireless Sensor Networks (WSNs) are an invaluable tool in agriculture. Currently these systems are good at reporting and logging data. Some recent work has focused on making the data useful and actionable. The next step in WSNs is the ability to automatically use that data for irrigation control. This can help minimize labor and reduce water usage.

This work presents several methods of irrigation control based on WSN's. Local control methods let each node manage irrigation based on the attached sensors or based on a schedule. Global control lets a central base station signal an individual node to irrigate. Hybrid approaches combine global control with local schedule based control. Model based control is an example of advanced global control where a plant model is used to determine when to irrigate and for how long. This work also explores different irrigation pulse types. Using different pulse types lets growers optimize irrigation by applying water in pulses instead of in a constant flow. This system is currently deployed and being tested in different types of agricultural environments.

Keywords. wireless sensor network, irrigation, control, wsn, actionable, interface, precision

The authors are solely responsible for the content of this technical presentation. The technical presentation does not necessarily reflect the official position of the American Society of Agricultural and Biological Engineers (ASABE), and its printing and distribution does not constitute an endorsement of views which may be expressed. Technical presentations are not subject to the formal peer review process by ASABE editorial committees; therefore, they are not to be presented as refereed publications. Citation of this work should state that it is from an ASABE meeting paper. EXAMPLE: Author's Last Name, Initials. 2012. Title of Presentation. ASABE Paper No. 12----. St. Joseph, Mich.: ASABE. For information about securing permission to reprint or reproduce a technical presentation, please contact ASABE at rutter@asabe.org or 269-932-7004 (2950 Niles Road, St. Joseph, MI 49085-9659 USA). 


\section{Introduction}

Irrigation control is a critical task in agricultural enterprises. The role of irrigation manager is important and the change of an irrigation manager can have significant effects on crop health and yields. The irrigation manager must be able to account for the different species water usages, season, micro climates, and plant developmental requirements (Lea-Cox 2011). In prior work Wireless Sensor Networks (WSN's) have been used to aid irrigation managers and growers in monitoring environmental conditions such as soil moisture to determine irrigation requirements (Kohanbash et al., 2011, Kohanbash et al., 2012). This work explores using WSN's for irrigation control and as an integrated platform that is aware of micro climate changes to yield more efficient irrigation.

For this work the CMU sensorweb basestation is used (Figure 1)(Kohanbash et al., 2011). This basestation is compatible with both a custom CMU node as well as a node developed by Decagon Devices. Both nodes are equipped with relays capable of controlling standard irrigation solenoids. This system is deployed in over a dozen field sites.

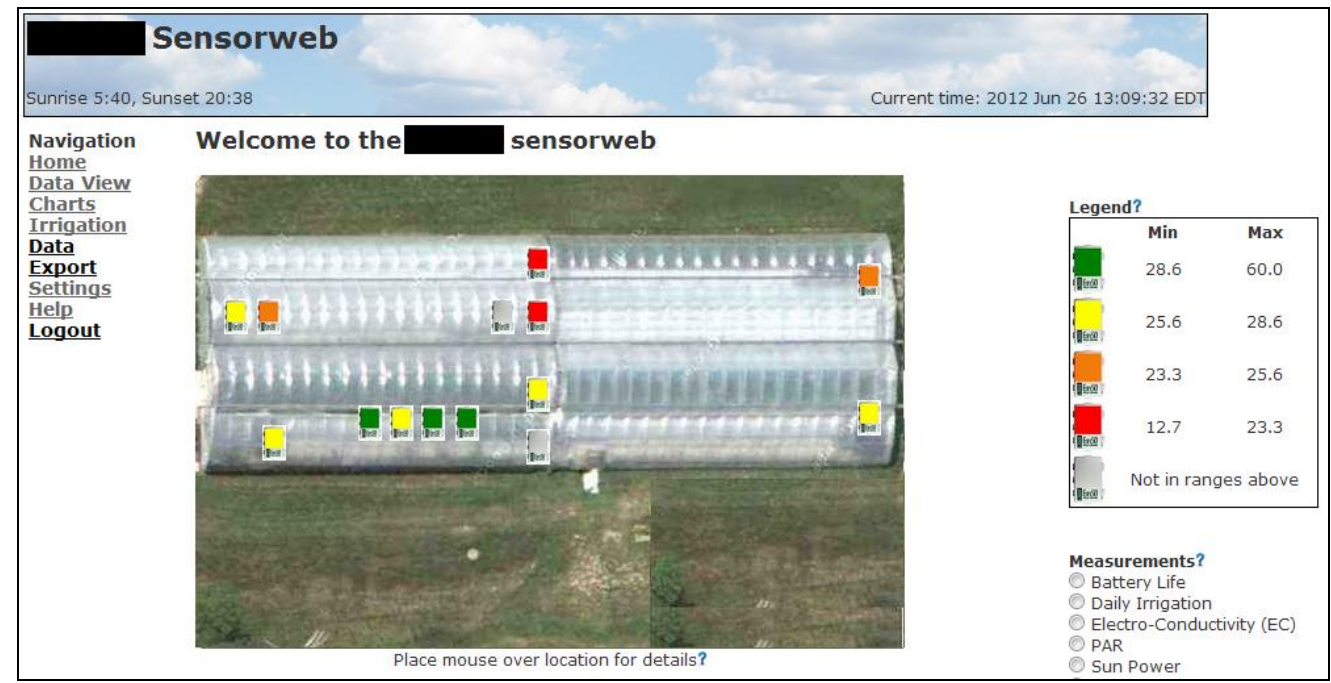

Figure 1. Image showing homepage of the CMU sensorweb basestation that is used for this work.

By utilizing WSN nodes with onboard relays capable of controlling solenoids growers can fine tune irrigation for increased efficiency, productivity and profitability while minimizing impact on wildlife and the environment (Ruiz-Garcia et al., 2009). By using small WSN nodes, large centralized controllers can be removed and replaced with nimble easily reconfigurable controller nodes. Some WSN nodes allow for DC latching solenoids and do not require running external power for the solenoid making installation of these systems easier and more cost effective. The next section will describe some of the methods available for WSN based distributed control.

\section{Control Methods}

WSN based irrigation is by nature a distributed system. This allows for precise control over specific irrigation zones. However, while distributed, WSN systems typically provide a user interface allowing for centralized monitoring and configuration of these remote nodes (Figure 2) (Kohanbash et al., 2012). 


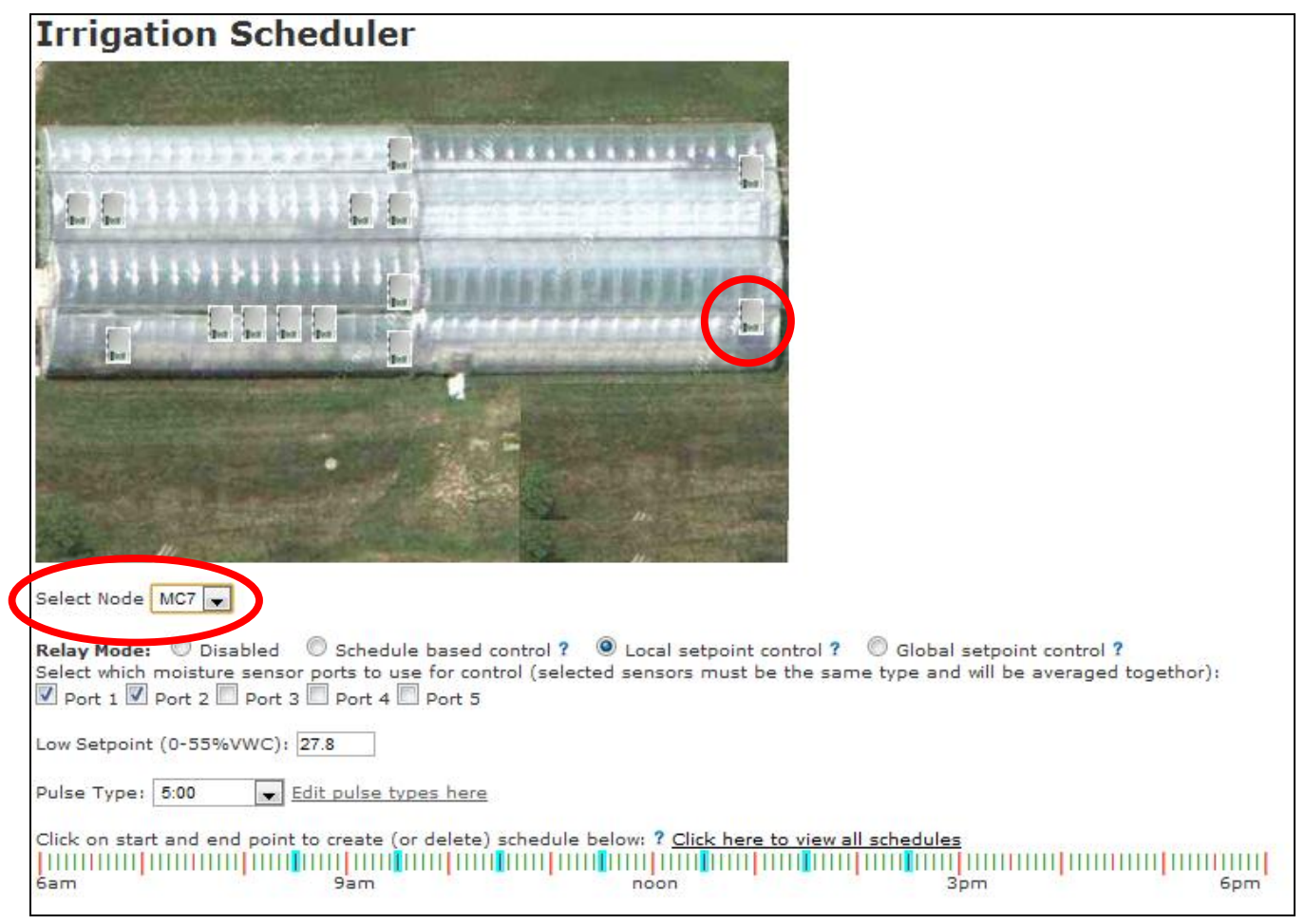

Figure 2. Primary irrigation configuration page. Users select nodes either by clicking the map image or by picking it from the drop down box.

Before delving into specific irrigation regimes a discussion of pulse types is necessary. Current irrigation systems typically turn irrigation on and off in large discrete time periods (large is relative based on the crop). This system allows for sub pulses within the large discrete time period. For each time interval (5 minutes in this system) there are three parameters that affect the pulse type; time on, time between pulses, and number of pulses (Figure 3). For example with a time interval of five minutes if we set time on to 1 minute, time between cycles to 1 minute and number of cycles to 2, the net result would be 2 minutes of irrigation per 5 minute cycle. By changing pulse types precise time control can be attained. Pulse types allow other irrigation methods to be more effective, for example if the pulses are spread out it leaves time for the sensors to read accurate values before deciding on the next irrigation cycle. Another advantage of varied pulse types is for weak irrigation systems, by varying the pulse type irrigation lines can be charged and primed in order to maintain proper pressure for irrigation. 


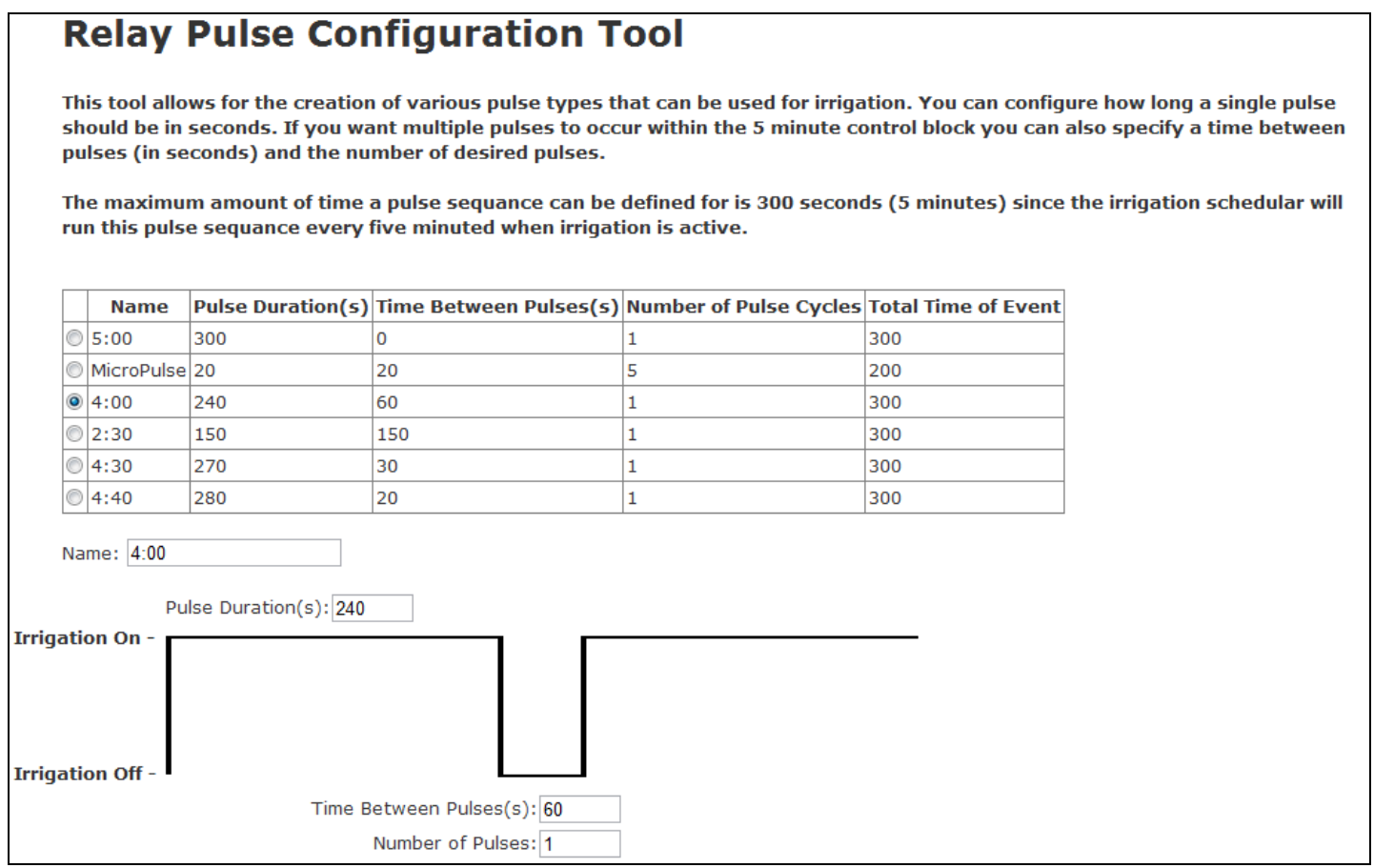

Figure 3. This is the primary tool for configuring pulse types. The graphic on the bottom shows a pictorial view to help set the pulse type parameters.

\section{Manual Control}

Manual control is the most basic level of irrigation command. This command lets users activate irrigation from anywhere. Utilizing the central base station software manual control can be sent specific to any node for precise control. This function has proved useful for growers who want to be off site while still controlling irrigation and not relying on automation and "new technology". Manual control also benefits from the WSN system. As growers, consultants, and extension specialists gain experience with using WSN systems they can develop irrigation rules based on an understanding of the soil moisture levels. For example, at one commercial greenhouse, they have learnt how to control plant quality based on soil moisture. Irrigation now has predictable results and is not dependant on the grower. Furthermore they can change their crop from Grade A (the most valuable) to Grade B (less valuable, but can be produced in greater quantity) as the market demand changes.

\section{Schedule Based}

Schedule based control is similar to current commercial systems that allow for irrigation based on a set clock. This system allows for the schedule to be set in five minute intervals with finer resolutions attainable by utilizing pulse types. Since the schedule is sent and stored in the node even if radio communication is lost between the base and the node irrigation will still occur. This schedule forms the basis of allowing other irrigation methods to work. The local and global control signals discussed below are logically AND'ed with the schedule to determine if irrigation should be allowed or not, ensuring that both the schedule and the controller allow irrigation at that time period. The schedule acts as a safety net by making sure irrigation cannot occur 
outside of the grower specified time. This is also useful in cases where water is limited; growers can cycle between crops while still allowing local and global control to be active.

\section{Local Control}

Local control allows the node to do setpoint control using "local" sensors that are attached to the node performing the irrigation control. In addition to let the grower be hands off and not manually turning irrigation on this allows the soil moisture levels to be smoother than a human could practically achieve (Figures $4 \& 5$ ) which is a benefit for many plants (there are some plants that this is not ideal for). Local control also allows for the node to loose communication with the nodes and still work. One of the key limitations to local control is that only onboard sensors can be used for determining control.

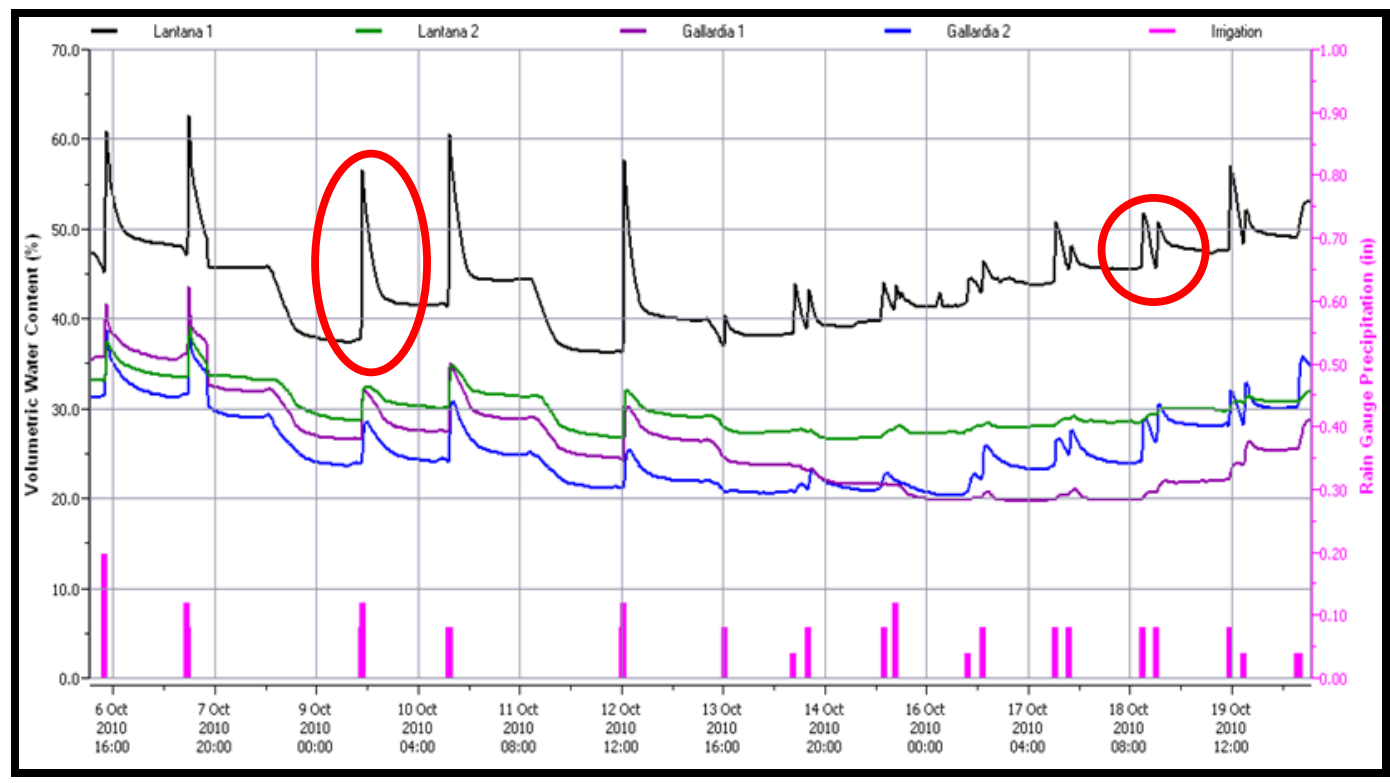

Figure 4. The above plot shows irrigation event bars and soil moisture in 5 pots at the Evergreen nursery. The left side of the plot has once daily irrigation. The sudden dropoff in soil moisture values indicates leaching. The right side of the plot has twice daily manual irrigation and demonstrates less leaching (Van lersel 2012). 


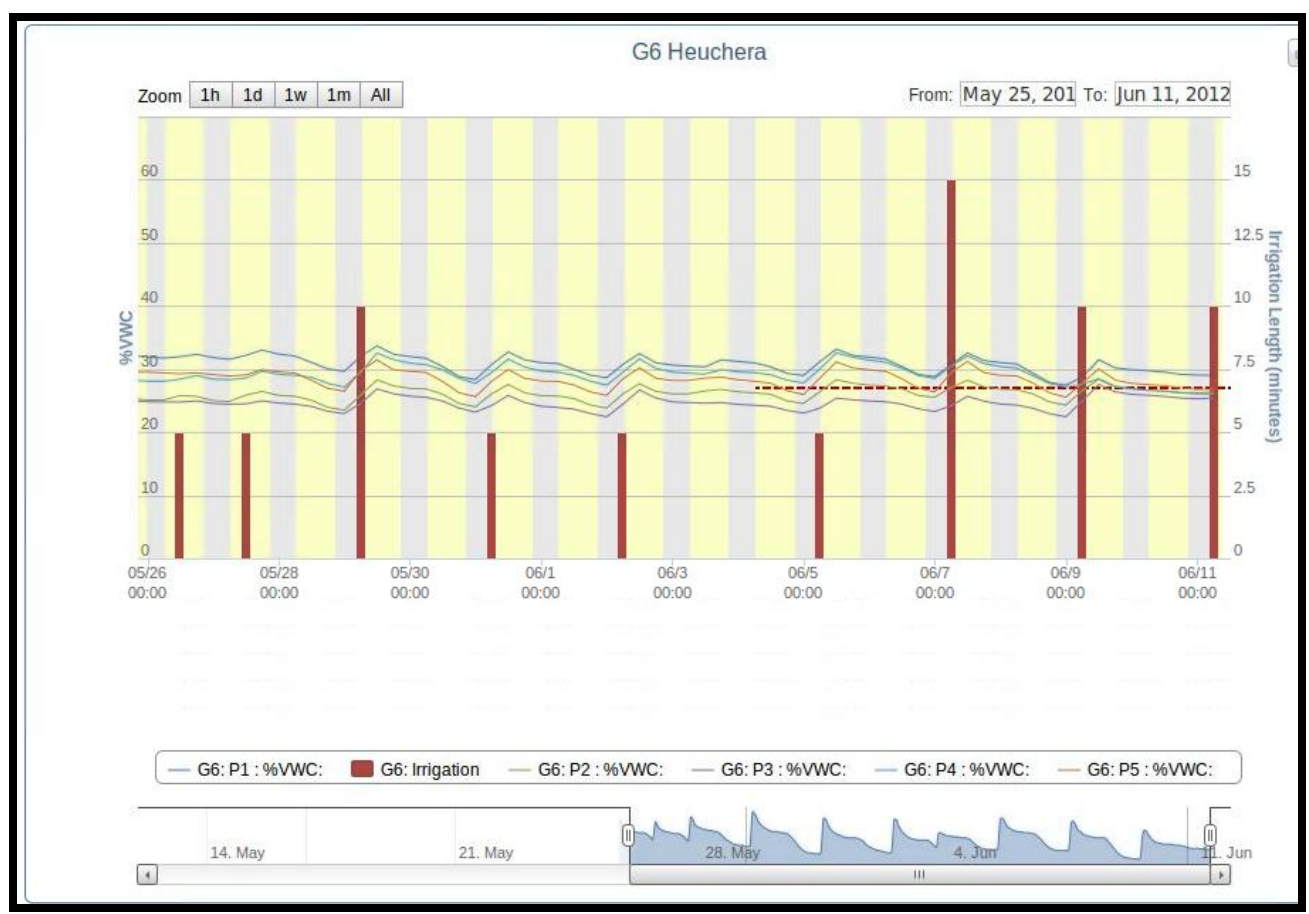

Figure 5. This is a similar plot from Evergreen with WSN based local control. The soil moisture has no large peaks which is better for this crop and does not exhibit any signs of leaching (Van lersel 2012).

\section{Global Control}

To overcome the limitations of local control, global control was developed. Global control allows the base station to determine when irrigation should occur based on more advanced criteria. This can be based on something as simple as a setpoint using a sensor from a different node to controlling irrigation based on complex mechanistic models (Bauerle, W.L., et al., 2006).

Model based control builds upon global control and is a key element to advanced control methods. Kohanbash (2012) discusses a framework for easily adding models into a WSN' base station system. It now appears possible to predict hourly plant water use with precision, using models and environmental data provided by the WSN network. (Lea-Cox 2011). Model based control can also maintain sliding setpoint for crops that do not want a static setpoint for soil moisture. These models developed by the plant science community are leading the way for precision irrigation systems to reach the next level of precise irrigation control.

\section{Results}

Preliminary results have shown many benefits provided by WSN's. With just monitoring of soil moisture data many of the sites using this system have shown water savings. By using this technology growers have been able to choose substrates that minimize leaching and choose fertilizers that work well for the substrate. Flowers by Bauers a commercial greenhouse in Maryland has reported better quality crops, less disease, and cutting irrigation times almost in half by just monitoring soil moisture (and not using the WSN for irrigation). With the addition of nodes that control irrigation and maintain a setpoint they were able to reduce that almost in half again for a combined irrigation reduction of $62 \%-75 \%$ savings (Table 1) (Bauers 2012). 
Table 1. Irrigation Improvements by utilizing a WSN system

\begin{tabular}{l|c}
\hline \multicolumn{1}{c|}{ System Status } & Irrigations Per Day \\
\hline Before WSN System Installed & 8 \\
WSN System: Only Monitoring & $4-5$ \\
WSN System: Monitoring \& Control & $2-3$ \\
\hline
\end{tabular}

\section{Conclusions}

Wireless sensor networks are a valuable tool to improving growing environments and for irrigation. Preliminary results have shown a large value in local control. As global control gets expanded the benefits will increase. Providing the ideal amount of water to the plants not only creates healthy plants but helps keep disease and pests away.

\section{Future Work}

There is a lot of future work that is needed to continue expanding WSN based irrigation. Creating a table that has suggested setpoints for a given crop and substrate would be very useful and make these systems easier to integrate. Expanding the models available for controlling irrigation to specific species is essential for saving water and being able to realize the benefits or precise irrigation control. Another important feature is adding the ability for the node/basestation to detect faulty sensor data. This can be complex since there are many causes of bad sensor data ranging from sensors falling out of the growing pot, to rocks near the sensor, to the sensor malfunctioning.

\section{Acknowledgements}

We gratefully acknowledge the USDA for supporting us with the USDA-NIFA Specialty Crops Research Initiative Award \# 2009-51181-05768. This support has made this research and development possible. The authors would also like to thank Todd Martin of Decagon Devices for all of his help and advice.

\section{References}

Bauerle, W.L., D.J. Timlin, Ya.A. Pachepsky, and S. Anantharamu. 2006. Adaptation of the biological simulation model MAESTRA for use in a generic user interface. Agronomy Journal, 98:220-228.

Bauers C. "SCRI-MINDS Year 3 Milestones Report”. Pullman WA. June 2012

Kohanbash D., Valada, A. \& Kantor, G.A. (2011). Wireless Sensor Networks and Actionable Modeling for Intelligent Irrigation. Amer. Soc. Agric. Biol. Eng. 7-12th August, 2011. Louisville, KY. Paper \#1111174. 7p.

Kohanbash D., Valada, A. \& Kantor, G.A. (2012). Base Station Design and Architecture for Wireless Sensor Networks. Commission of Agricultural and Biosystems Engineering (CIGR). 8-12th July, 2012. Valencia Spain. 
Lea-Cox, J. D. 2012. Using Wireless Sensor Networks for Precision Irrigation Scheduling. Chapter 12. In: Problems, Perspectives and Challenges of Agricultural Water Management. M. Kumar (Ed.) InTech Press. Rijeka, Croatia. pp. 233-

258. http://www.intechopen.com

Ruiz-Garcia, L., Lunadei, L., Barreiro, P. \& Robla, J. I. 2009. A Review of Wireless Sensor Technologies and Applications in Agriculture and Food Industry: State of the Art and Current Trends. Sensors 9: 4728-4750.

Van lersel M. “SCRI-MINDS Year 3 Milestones Report”. Pullman WA. June 2012 